\title{
National Support for World Order
}

\author{
A RESEARCH REPORT
}

ROBERT C. ANGELL

Department of Sociology

University of Michigan

The research aims to discover the causal factors that make some nations more supportive of world order than others. Seven indicators of national support for world order are identified. Scores on them and on a combined index for 114 nations are obtained. Switzerland and three Scandinavian nations rank at the top, the United States is at rank 40 , and the Soviet Union at 72 . Five significant causal factors are identified, which yield a multiple correlation coefficient of .69 with the Index of National Support for World Order. The most powerful predictor is the degree to which citizens of a nation participate in international nongovernmental organizations. Less powerful are national levels of enlightenment, urgency of foreign trade, productivity relative to reference nations, and, negatively, population pressure.

\section{$\mathbf{I}_{\mathrm{n}}$} the Middle East, and widespread disillusion with the United Nations, it may seem quixotic to pursue research on factors conducive to national support for world order. Yet, if it is a time of disappointing performance, it is also a time of great need and encouraging potentiality. Nuclear weapons pose a threat that makes men actively seek a global solution, and modern communication and travel offer hopeful means for reaching the minimum consensus necessary.

AUTHOR'S NOTE: The computer analysis for this study was supported from unsponsored research funds of the University of Michigan allocated to the Sociology Department. I wish to acknowledge the competent and patient computer advice and service given me by E. Daniel Ayres and Robert C. Jackson. I have also had able assistance from Michael W. Traugott, Assistant Director of the Historical Archive of the Inter-University Consortium for Political Research. My colleague, J. David Singer, has made helpful suggestions and has kindly provided data from his project, the Correlates of War. All data used in the section on dependent variables are now on deposit with the Inter-University Consortium for Political Research, Ann Arbor, Michigan 48106. 
The rationale of this research was stimulated by Charles $H$. Cooley's (1918: ch. 1) theory of "the tentative process." He believed that, in the growth of social institutions, there is constant experimentation, often unconscious, as each institution copes with its problems. The successful experiments survive and form the basis for further growth. Thus, the future is embryonic in the present and is somewhat predictable if we can foresee the crescive outcomes. This theory is here applied to nation-states. It is assumed that some nations are in the forefront of experimentation toward world order, that they are coping with the problem of making the transition from narrow nationalism as the world has known it historically to a more enlightened nationalism that will support world order. If the world is to become "spaceship earth" some day, it is these nations that are the pioneers.

This situation offers a rare opportunity to the social scientist. If he can positively identify these pioneering nations, he can seek the causal factors that are leading them to be supportive of world order. And, if among these causal factors there are policy choices not compelled by unique exigencies, such choices may recommend themselves to men of good will in other nations. Thus, social research may make a contribution to the cause of world order by indicating points at which effort will be effective.

National support for world order is a concept difficult to define, yet it must be defined if the research is to have meaning. An easy way out would be to offer an operational definition, to say that support for world order is what instruments used to measure it measure. But that is not good enough. There is some notion, however vague, that dictates the selection of those instruments. Perhaps we can approach the matter by enumerating the terms I used at earlier stages in the research: receptivity to world responsibilities, willingness to take world responsibilities, world-mindedness, and concern for world order. I gave up the first because it seemed too passive, the second because it emphasized potentiality rather than actuality, the third because it had a broad, intellectual focus rather than a practical one, the fourth because the degree of national concern is too elusive to measure reliably. I chose "support for world order" as indicating action, not thought or feeling, and as focused on the systematic relations among nations. National support for world order, as the criterion variable for this research, can thus be defined as: "efforts and activities that foster the development of a system of relations among nations capable of creating and maintaining world peace." Since this is a variable, its value for any nation may be high or low. There may even be nations that actively oppose world order. 
The first objective of the research, then, has been to obtain valid measures of national support for world order. Since it seemed unlikely that there is a single indicator available that would adequately represent the central concept, I searched for several that could be used separately and could be combined to form an index. The search was not easy, because I wanted the ultimate generalizations to have universal scope. The indicators chosen had therefore to be ones for which there were accurate data for the great majority of nations. The paucity of such data has strictly limited the number of possible indicators. Seven out of a larger number considered have been chosen. Since work was begun in 1969 when data were just becoming available for the middle sixties, the indicators for the most part have been centered on the years 1963-1967.

\section{The Dependent Variables}

\section{CONTRIBUTIONS/ASSESSMENTS}

The first variable used was suggested to me by Chadwick Alger (for a working paper discussing six of the seven separate dependent variables, see Angell, 1971: 19-30). It is the ratio of the amount that a nation contributes voluntarily to agencies of the UN system to its assessments for the support of that system. The rationale was that the greater the commitment of a nation to world order, the more of its substance it will give freely to help create that order. The numerator of the fraction is composed of the voluntary contributions made to the Expanded Program of Technical Assistance, the UN Special Fund, UNICEF, and the UN/FAO World Food Program during the years 1961-1968. The denominator is composed of the assessments for support of the United Nations, the International Labor Organization, the Food and Agricultural Organization, UNESCO, the World Health Organization, the International Atomic Energy, and the International Civil Aeronautics Organization (minus the 1968 assessment for the ICAO). The ratios range from 488.77 for Norway to 1.51 for Somalia. The basic data are drawn from the Supplements to the Official Records of the General Assembly for the appropriate sessions and from the issues of the $U N$ Yearbook.

\section{ABSENCES AND ABSTENTIONS}

The second indicator is based on roll call votes in the UN General Assembly for the fifteenth through the twenty-second sessions 
(1960-1968), and the third and fourth special sessions (1961 and 1963)-401 roll call votes in all. The handling of absences is straightforward: the fewer absences, the greater the nation's assumed support for world order. The handling of abstentions, however, is more complicated. I have assumed that abstentions are sometimes statesmanlike acts that express unwillingness to embrace either horn of an unwisely posed dilemma. Inspection of the data led me to believe that approximately $15 \%$ of all votes cast were "statesmanlike abstentions." I reached this conclusion because this was the point that divided the Communist nations (all of whom had a lower rate of abstentions) from the Western nations (all of whom had a higher rate), and because India, a then Western-leaning and statesmanlike nation, had $16 \%$ abstentions, and Yugoslavia, a Communist but politically independent nation, had $13.9 \%$. This conclusion was further buttressed by a plotting of the contributions/assessments scores against the abstentions to determine the point at which the former were highest. It proved to be at $15.8 \%$ abstentions. Thus, the nations showing the strongest support on the previous indicator tended to abstain about $15 \%$ of the time. The abstention score of a nation was made proportional to the degree that its percentage of abstentions deviated from $15 \%$ in either direction. Absences and abstentions were combined so as to give each component of the indicator approximately equal weight.

\section{DIPLOMATIC REPRESENTATION}

The third indicator derives from data gathered by Robert Keohane (1969) showing the average size of national delegations to the United Nations (1961-1966), together with the data previously published by Chadwick Alger and Steven J. Brams (1967) on numbers involved in bilateral diplomatic representation (1963-1964). The purpose of this indicator is to measure the relative importance nations attribute to the United Nations in foreign policy. This is achieved by dividing the average size of a nation's UN delegation by the average size of its bilateral embassies. The scores on this indicator range from 11.54 for Canada to 1.64 for South Africa.

\section{BILATERAL TREATY REFERENCES}

The fourth indicator expresses the degree to which nations agree to use UN agencies in matters covered by bilateral treaties. The data are drawn from the UN Treaty Project of Peter H. Rohn (1968) at the University of 
Washington. He has supervised the coding of all treaties registered with the United Nations, and his project has made available computer printouts of data that scholars desire. The item of particular interest here was the number of nonnominal references to UN institutions in state-state treaties. The measure used is the ratio of the number of such references to the number of state-state treaties. Scores are omitted for nations having less than ten treaties recorded. Analysis showed that the nations in being as independent states in 1933 tended to have much lower ratios than those that became independent during and after World War II. To offset this tendency, I treated the two sets of nations as independent groups, determining separate means and standard deviations for each group, but consolidating the two sets of standard scores in a single array. Scores range from .67 for Switzerland to .00 for Jamaica and Mongolia.

The first four indicators are related in one way or another to the United Nations: financial commitment to it, voting responsibility in it, relative diplomatic weight accorded it, and use of the UN system as an instrument in bilateral treaties. Since the United Nations and its agencies are by no means the only channel through which nations can work toward world order, three other indicators were developed.

\section{COOPERATION/CONFLICT}

The assumption on which the fifth indicator is based is that nations whose governments are cooperative bilaterally with those of other nations are supporting world order. The data employed come from the World Event/Interaction Survey conducted under the supervision of Charles A. McClelland of the University of Southern California. They represent careful coding of all copies of the New York Times for January 1966 through August 1969. Data tapes had been obtained from WEIS by Raymond Tanter at the University of Michigan for use in his Voluntary International Coordination Project. He kindly included a small computer run of these data, which counted the number of cooperative and conflictual acts and gestures for each nation toward all other nations. The categories of cooperative and conflictual acts and gestures were determined by me after careful study of the factor analysis of McClelland and Hoggard (1969) of the WEIS data. ${ }^{1}$ The indicator is the number of

1. In Table 2 on page 718 , the authors collapse their 65 categories into 47 , of which 25 are classified as cooperative/collaborative behavior types and 22 as conflictual behavior types. Of these 47,38 were accepted as classified. Seven were omitted as ambiguous according to the authors' factor analysis. The first 4 of these 7 
cooperative acts and gestures as a percentage of all acts and gestures in both cooperative and conflictual categories. The scores range from 94.7 for Finland to 18.2 for El Salvador.

\section{RED CROSS CONTRIBUTIONS}

The sixth indicator consists of the contributions of the government and people of each nation to the International Committee of the Red Cross and associated organizations, divided by its gross national product. Since the contributions of governments greatly exceed those from private citizens and groups, I felt it proper to use this as an indicator of national support. A score on Red Cross contributions is the amount subscribed for the years 1963-1969 divided by the GNP in 1966. Switzerland has much the highest ratio (the International Committee of the Red Cross is a Swiss corporation). Eighteen of the 114 nations made no donation during the seven years and thus scored 0 . The data come from annual financial reports published in the official organ of the International Committee of the Red Cross, International Review of the Red Cross.

\section{IGO MEMBERSHIPS}

The final indicator attempts to express the support shown by nations for intergovernmental organization outside the UN system. A review of all such IGOs in the 1966-1967 edition of the Yearbook of International Organizations revealed only five that had more than sixty members each and were potentially universal in the sense that they had no regional, religious, ideological, or ethnic basis. Also, their objectives were such as to be potentially of interest to all nations. These organizations are the International Bureau of Education, the International Committee of Military Medicine and Pharmacy (which promotes professional collaboration in the spirit of the Geneva Convention), the International Office of Epizootics (which promotes research on the pathology and prophylaxis of contagious diseases of livestock internationally), the International Union for the Publication of Customs Tariffs, and the Permanent Court of

had been assumed to be positive: consult (host a meeting); grant (return of persons or property); request (information or policy assistance); and request (material assistance). The last three had been assumed to be negative: protest (complain); warn; and reduce relationship (cancel planned event). Two categories that had been assumed to be negative had factor loadings that persuaded me to regard them as positive: deny (accusation); and deny (policy, action). 
Arbitration. Scores were assigned from 0 to 5 according to the number of these organizations to which nations bclonged.

\section{RELATIONS AMONG THE DEPENDENT VARIABLES}

The 114 nations that could be scored on five or more of these seven indicators of national support for world order are included in this study. Of these, four are not members of the United Nations and do not, therefore, have scores on absences and abstentions. They do, however, have contributions/assessments scores because they belong to Specialized Agencies of the UN system. All 114 nations have scores on IGO memberships also. One nation (Mongolia) has no score on Red Cross contributions because its GNP was not recorded. For want of the necessary data, there are only 100 nations on diplomatic representation, and 88 on cooperation/conflict. Because nations with fewer than 10 treaties recorded were omitted, there are only 94 nations on bilateral treaty references. All correlations are based on only those nations that have scores on each of the variables being correlated.

Since the indicators are all assumed to refer to national support for world order, it becomes important to see to what extent they are in fact interrelated. Table 1 gives the intercorrelation matrix. It will be seen that

\section{TABLE 1}

INTERCORRELATIONS OF SEVEN INDICATORS OF NATIONAL SUPPORT FOR WORLD ORDER

\begin{tabular}{|c|c|c|c|c|c|c|}
\hline & 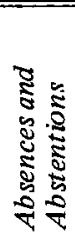 & 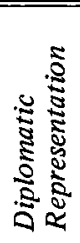 & 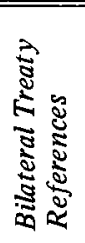 & 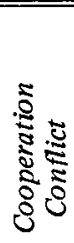 & 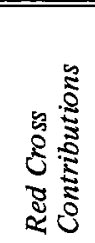 & $\begin{array}{l}\frac{2}{1} \\
\frac{5}{5} \\
0 \\
0 \\
0 \\
0 \\
0 \\
0\end{array}$ \\
\hline Contributions/Assessments & .30 & .43 & .32 & .26 & .18 & .17 \\
\hline Absences and Abstentions & & .19 & .23 & .21 & -.06 & .16 \\
\hline Diplomatic Representation & & & .05 & .24 & -.16 & .25 \\
\hline Bilateral Treaty References & & & & .18 & .38 & .15 \\
\hline Cooperation/Conflict & & & & & .07 & .25 \\
\hline Red Cross Contributions & & & & & & .06 \\
\hline
\end{tabular}

NOTE: $\mathrm{N}$ varies between 79 and 114 . For those interested in statistical significance levels, coefficients above .25 would be significant at the .01 level (one-tailed test). 
six of the seven indicators are positively related to one another in every case. Red Cross contributions is the only one that has negative relations: -.06 with absences and abstentions, and -.16 with diplomatic representation. The fact that in these instances an indicator not involving the United Nations is being related to two indicators that do involve the United Nations suggests the advisability of looking at the correlations within each of these two groups and between them. The mean of the six correlations among United Nations-related indicators is .25; that of the three correlations among non-united Nations-related indicators is .11 ; and that of the twelve correlations that bridge the two groups is .16. These results are not surprising since the non-United Nations-related indicators could hardly be more dissimilar. The mean correlation for all 21 correlations is .18 . This shows that the indicators are fairly independent of one another and thus express different facets of support for world order. Since even the most divergent one-Red Cross contributions-has a mean positive correlation of .08 with the others, it can be said to be a valid, if weak, indicator of national support for world order.

From the start, I wanted to develop and use an Index of National Support for World Order in addition to using the separate indicators. The question arises: Should such an index be weighted or unweighted? Although a weighted index based on the strength of intercorrelations among the indicators themselves was developed and used in the early analysis, it has been abandoned in favor of an unweighted index because the latter makes fewer assumptions and because the multiple correlation of the independent variables with it is only slightly lower than that with the weighted index. The score for each nation on the unweighted index, hereafter called the NSWO Index, is simply the mean of the standard scores on the indicators available for each nation-usually seven, but in some cases six or five.

Scores on the NSWO Index are given in Table 2. They offer an opportunity for those knowledgeable about international affairs to judge the validity of the index. A few observations may aid that judgment. The five Scandinavian nations rank at 2,3,4,20, and 27. The British Commonwealth nations spread from Canada at rank 7 to Malta at rank 114; the Arab nations, from Kuwait at 5 to Yemen at 108. The six original Common Market nations are found at from 8 to 55, and the members of the Communist bloc from 51 to 112. Yugoslavia, however, is at rank 28 . Latin American nations spread from Colombia at 31 to El Salvador at 110.

It is worthwhile to note that, as is to be expected when seven indicators are being combined, the distribution of scores is very compressed. 
Although the scores for each indicator were computed so as to have a mean of 50 and a standard deviation of 10, the NSWO Index scores have a standard deviation of only 5.56 from mean of 49.90 . There are only 12 nations scoring more than one standard deviation above the mean and 16 nations scoring more than one standard deviation below. That three Scandinavian nations are among the top faur and nations from three continents are among the bottom four are points of interest.

\section{The Independent Variables}

The procedure used in this analysis, the examination of hypotheses with simple and multiple correlations between the chosen independent variables (predictors) and the dependent variables (the NSWO Index and its component elements), may appear to some to be a simplistic approach to the problem. The use of modern procedures for examination of the structure of causal relations such as path analysis and the use of various forms of time-series analysis are left to those who can obtain more accurate data and develop more refined theoretical formulations of the problem. I saw no utility for such methods given the data which are analyzed here.

For the dependent variables, the main problem was to obtain valid indicators of the central concept, national support for world order. For the independent variables, the problem has been quite different-to find a small set of national characteristics that would be maximally predictive of scores on the seven separate indicators and the NSWO Index. Since the criterion variables express governmental policy, the predictors may be any characteristics of the nation that might affect that policy. The search for a set of predictors has been guided by social science theory. Since the power, jointly and severally, of the predictors is most easily shown by multiple regression analysis, and since accurate specification of the power of each predictor separately requires that predictors be fairly independent of each other (not closely correlated), a second aim has been to find predictors possessed of such independence. The second objective, unfortunately, has not been reached.

\section{INGO PAR TICIPATION}

The research for Angell (1969) indicated that transnational participation of several kinds probably had significant influence on national foreign 
TABLE 2

SCORES OF 114 NATIONS ON THE INDEX OF NATIONAL SUPPORT FOR WORLD ORDER

\begin{tabular}{|c|c|c|c|c|c|}
\hline \multirow[t]{5}{*}{1.} & Switzerland & 73.47 & 41. & United Kingdom & 51.88 \\
\hline & Denmark & 63.96 & & Jordan & 51.64 \\
\hline & Sweden & 62.92 & & Sierra Leon & 51.54 \\
\hline & Norway & 62.04 & & Burma & 51.42 \\
\hline & Kuwait & 59.23 & & Venezuela & 51.37 \\
\hline \multirow[t]{5}{*}{6.} & Ivory Coast & 58.32 & 46. & Ethiopia & 51.04 \\
\hline & Canada & 57.14 & & Tunisia & 50.92 \\
\hline & German F.R. & 56.76 & & Taiwan & 50.83 \\
\hline & Austria & 56.62 & & Togo & 50.77 \\
\hline & Thailand & 56.59 & & Portugal & 50.60 \\
\hline \multirow[t]{5}{*}{11.} & Iran & 56.28 & 51. & Hungary & 50.39 \\
\hline & Lebanon & 55.66 & & Ghana & 50.36 \\
\hline & United Arab R. & 55.47 & & Spain & 50.14 \\
\hline & Luxemburg & 55.46 & & Peru & 50.09 \\
\hline & Netherlands & 55.40 & & France & 49.95 \\
\hline \multirow[t]{5}{*}{16.} & Liberia & 55.36 & 56. & Israel & 49.92 \\
\hline & Japan & 55.16 & & Zaire & 49.78 \\
\hline & Australia & 55.14 & & South Korea & 49.70 \\
\hline & New Zealand & 55.00 & & Senegal & 49.69 \\
\hline & Finland & 54.76 & & Afghanistan & 49.62 \\
\hline \multirow[t]{5}{*}{21 . } & Pakistan & 54.47 & 61. & Mali & 49.56 \\
\hline & Ireland & 53.90 & & Romania & 49.42 \\
\hline & Morocco & 53.68 & & Nigeria & 49.41 \\
\hline & Italy & 53.56 & & Ceylon & 49.32 \\
\hline & Iraq & 53.54 & & South Vietnam & 49.16 \\
\hline \multirow[t]{5}{*}{26.} & Greece & 53.15 & 66. & Algeria & 48.78 \\
\hline & Iceland & 52.95 & & Czechoslovakia & 48.59 \\
\hline & Yugoslavia & 52.87 & & Malaysia & 48.35 \\
\hline & Philippines & 52.86 & & Cameroons & 48.28 \\
\hline & Turkey & 52.77 & & Nicaragua & 48.25 \\
\hline \multirow[t]{5}{*}{31.} & Colombia & 52.73 & 71. & Guinea & 47.99 \\
\hline & Sudan & 52.72 & & U.S.S.R. & 47.86 \\
\hline & Chile & 52.65 & & Cuba & 47.79 \\
\hline & Brazil & 52.59 & & Guatemala & 47.67 \\
\hline & Mexico & 52.52 & & Poland & 47.51 \\
\hline \multirow[t]{5}{*}{36.} & Indonesia & 52.48 & 76. & Bolivia & 47.51 \\
\hline & India & 52.48 & & Central Afr. $\mathrm{R}$. & 47.42 \\
\hline & Belgium & 52.38 & & Argentina & 47.28 \\
\hline & Saudia Arabia & 52.13 & & Nepal & 47.10 \\
\hline & United States & 52.12 & & Laos & 47.03 \\
\hline
\end{tabular}


TABLE 2 (Continued)

\begin{tabular}{|c|c|c|c|c|c|}
\hline \multirow[t]{5}{*}{81.} & Bulgaria & 46.94 & 101. & South Africa & 43.65 \\
\hline & Malagasy R. & 46.92 & & Dahomey & 43.37 \\
\hline & Ecuador & 46.92 & & Somalia & 43.34 \\
\hline & Tanzania & 46.88 & & Chad & 42.88 \\
\hline & Mauretania & 46.80 & & Gabon & 42.53 \\
\hline \multirow[t]{5}{*}{86.} & Libya & 46.76 & 106. & Kenya & 42.00 \\
\hline & Upper Volta & 46.54 & & Jamaica & 41.94 \\
\hline & Dominican R. & 46.40 & & Yemen & 41.60 \\
\hline & Cambodia & 46.39 & & Uganda & 40.96 \\
\hline & Panama & 46.09 & & El Salvador & 40.03 \\
\hline \multirow[t]{5}{*}{91.} & Niger & 45.94 & 111. & Albania & 39.78 \\
\hline & Syria & 45.89 & & Mongolia & 39.18 \\
\hline & Honduras & 45.75 & & Malawi & 38.79 \\
\hline & Paraguay & 45.68 & & Malta & 35.03 \\
\hline & Cosia Rica & 45.52 & & & \\
\hline \multirow[t]{5}{*}{96.} & Uruguay & 45.50 & & & \\
\hline & Haiti & 44.91 & & & \\
\hline & Cyprus & 44.40 & & & \\
\hline & Zambia & 44.06 & & & \\
\hline & Congo (Braz.) & 43.86 & & & \\
\hline
\end{tabular}

policy. The easiest of these to measure for the nations of the world was participation of nationals in international nongovernmental organizations (formerly labeled NGOs, more recently INGOs). In each edition of the Yearbook of International Organizations, there is listed for each organization the countries from which membership in that organization is drawn. The memberships may represent national groups-as, for instance, the American Sociological Association in the International Sociological Association-or they may represent individual citizens. Using the 1966-1967 edition of the Yearbook, I counted the INGOs of universal rather than regional scope in which each nation is represented, within the following sections of the Yearbook: Bibliography, press; Social sciences; International Relations; Agriculture; Transport, travel; Technology; Science; Education, youth; Health, medicine; Arts, literature, radio; and Sport, recreation. The following sections were omitted because they were not as applicable to nationals of all countries of the world as were those in the first set, and their inclusion might therefore bias the results: Religion, ethics; Politics; Law, administration; Social welfare; Professions, employers; Trade Unions; Economics, finance; and Commerce, industry. There were 523 appropriate INGOs listed in the sections covered. The scores, ranging from $\mathbf{4 9 5}$ for France to 0 for Yemen, were standardized. 


\section{ENLIGHTENMENT}

Karl Deutsch (1953: 126-130) demonstrates that citizen mobilization for intense social communication is significant for intelligent participation in the modern world. He emphasizes the reading of newspapers, listening to radio, and elementary education. Building on this idea, I constructed a predictor labeled enlightenment which combines the national data for newspapers per 1,000 population, radios per 1,000 population, and adjusted school enrollment, all for 1965, from Taylor and Hudson (1972). The national scores in each series were transformed into an array with mean 50 and standard deviation 10 and added.

\section{URGENCY OF FOREIGN TRADE}

The third predictor is derived from a suggestion of Johan Galtung (1967: 311-312). He theorized that a small country with a high gross national product per capita must engage in international trade to reap the benefits of its high division of labor. Conversely, a large nation with a low gross national product per capita does not have the means of developing an efficient domestic market, let alone import much from abroad. I have operationalized this idea by using the ratio of GNP per capita (1966) to the population of each nation (data are from the UN Statistical Yearbook). It seemed to me, however, that this predictor should also contain as a second component some measure of actual foreign trade, since the tendency to desire a stable world order is affected not merely by the need for trade but by the habit of it. Foreign trade is measured by the sum of imports and exports (1966) per capita (data from the same source). I standardized both components and, in the final composite index, added them together, but weighted the first (Galtung) part twice as heavily as the second.

\section{POPULATION PRESSURE}

The fourth predictor is negative rather than positive. It posits an obstacle to the support of world order rather than something conducive to it. The obstacle envisaged is population pressure. The hypothesis is that the more severe the population pressure, the fewer will be the resources, human and material, to support anything so remote as world order. Population pressure, however, is not just a matter of the rate of population growth. It is less or greater according to the nation's ability to cope wiin 
that growth. Population pressure has, therefore, been operationalized as the ratio of the standardized annual rate of growth (1960-1965) to the standardized measure of GNP per capita (1965); (data are from the $U N$ Demographic Yearbook).

\section{PRODUCTIVITY RELATIVE TO REFERENCE NATIONS}

The fifth and last predictor reflects a hypothesis somewhat inverse to that of population pressure. Whereas population pressure is hypothesized to distract attention and effort from global concerns, including support for world order, economic success relative to that of other nations felt to be "in the same league" is hypothesized to give a nation a sense of status among nations that leads it to participate in efforts to realize a more orderly world. The emphasis on other nations "in the same league" is important because it brings in the concept of reference group or category in a way that population pressure does not. There is little sense of relative deprivation under conditions of population pressure; the handicap may not be formulated at all. Relative economic success, however, is likely to be a source of pride, and relative failure a source of chagrin to informed citizens.

The reference groups chosen for this predictor are as follows: (1) the Latin American nations (21), including those in Central America, the Caribbean, and South America; (2) the developed Western nations (28), including West European nations, and South Africa, United States, Canada, Australia, New Zealand, Japan, Israel, and Turkey, (3) Communist Eurasian nations (9), including Yugoslavia and Mongolia; (4) Asian and North African nations (28), excluding Japan, Israel, and Turkey; and (5) sub-Saharan African nations (28), excluding South Africa. The scores on this predictor were developed from the ranks in each group. The top nations in each were scored 1.000 . Other scores depend on the number of nations in the group. Albania, for instance, the lowest in a group of nine, was scored .125, whereas Upper Volta, the lowest in a group of 28 , was scored .037 . These scores were then standardized.

\section{REJECTED PREDICTORS}

The five predictors that have been adopted were selected from a larger number considered. Some of the latter were rejected because data were not available for enough countries. Others either were so closely related to one of the five selected as to provide no new leverage or had correlations 
with the NSWO Index markedly inferior to those of the five. A list of these also-rans, together with the reasons for exploring each of them, follows:

(1) Military power (military manpower per capita, defense expenditures per capita, and defense expenditures/GNP); as representing a form of nationalism antithetical to support for world order.

(2) Internal security forces per square kilometer; as measuring domestic problems that would detract from support for world order.

(3) Domestic violence; as measuring domestic problems that would detract from support for world order.

(4) Political instability and social tension; as measuring social problems that would detract from support for world order.

(5) National dependence on one or more sponsoring countries; as relieving the nation of responsibility to support world order.

(6) Ethnolinguistic fractionalization; as making fractionalized nations more aware of the need for order at any level.

(7) Immigration; as bringing home to a nation the variety of peoples in the world and hence the need for world order.

(8) Years as an independent country; as measuring political maturity and hence awareness of the need for world order.

(9) The Political Representation Index developed by Phillips Cutright (1965: app. B) and used in the early stages of this research, but abandoned because it overlapped so heavily with enlightenment and INGO participation; as measuring domestic pluralism, a condition assumed to be conducive to participation in a collective world system.

(10) Degree of polyarchy of political system; as an alternative to the Political Representation Index (above).

(11) "PICA" Press Freedom Index; as an alternative to the Political Representation Index (above).

(12) Students abroad; as an alternative to INGO Participation.

\section{Relations of the Predictors to the}

Seven Separate Indicators

The first step in analyzing the research results is to examine the matrix of correlations between the independent and the dependent variables. This matrix is given in Table 3.

In examining the correlations it must be remembered that population pressure is different from the other four predictors in that it is 
TABLE 3

CORRELATIONS BETWEEN THE PREDICTORS AND THE SEVEN SEPARATE INDICATORS

\begin{tabular}{|c|c|c|c|c|c|c|c|}
\hline & 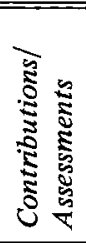 & 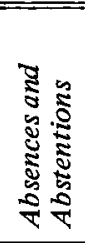 & 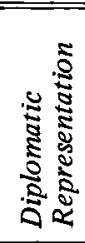 & 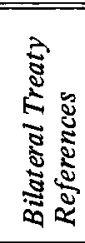 & 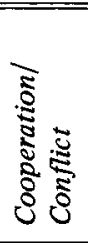 & 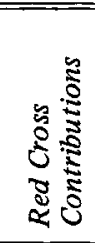 & 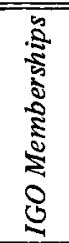 \\
\hline INGO Participation & .39 & .24 & .48 & .19 & .42 & -.00 & .62 \\
\hline Enlightenment & .44 & .17 & .30 & .05 & .33 & .05 & .41 \\
\hline Urgency of Foreign Trade & .35 & .07 & -.01 & .21 & .18 & .31 & .01 \\
\hline Population Pressure & -.03 & -.22 & -.07 & -.07 & .04 & -.07 & -.17 \\
\hline $\begin{array}{l}\text { Productivity Relative to } \\
\text { Keference Nations }\end{array}$ & .31 & .30 & .15 & .17 & .18 & .22 & .12 \\
\hline
\end{tabular}

NOTE: $\mathrm{N}$ varies between 88 and 114. For those interested in statistical significance levels, coefficients as high as .25 would be significant at the .01 level (one-tailed test).

hypothesized to have a negative effect on the indicators. Hence its (very slight) positive correlation with cooperation/conflict is unexpected. Other results contrary to the hypotheses are the trivial negative correlations between urgency of foreign trade and diplomatic representation, and INGO participation and Red Cross contributions (-.004).

It is apparent that the independent variables collectively are most successful in predicting contributions/assessments and IGO memberships. They are least successful in predicting Red Cross contributions and bilateral treaty references. Of the individual predictors, INGO participation is evidently the most powerful, and population pressure the least. It is noticeable that enlightenment has much the same pattern of relations with the indicators as INGO participation, but at a lower level of correlation. Urgency of trade and productivity relative to reference nations show some, but less, similarity of pattern.

These relationships are shown in a different way in Figure 1, which is based on all correlations of the predictors of more than .20 , both with the separate indicators and the NSWO Index. It is evident from Figure 1 that there is a broad tendency for enlightenment and INGO participation to predict cooperation/conflict, diplomatic representation, and IGO memberships, and for urgency of trade and productivity relative to reference nations to predict bilateral treaty references, absences and abstentions, and Red Cross contributions, with both pairs predicting contributions/assessments. The reasons for this broad tendency are not apparent. The single correlation of any importance with population pressure, that of absences 


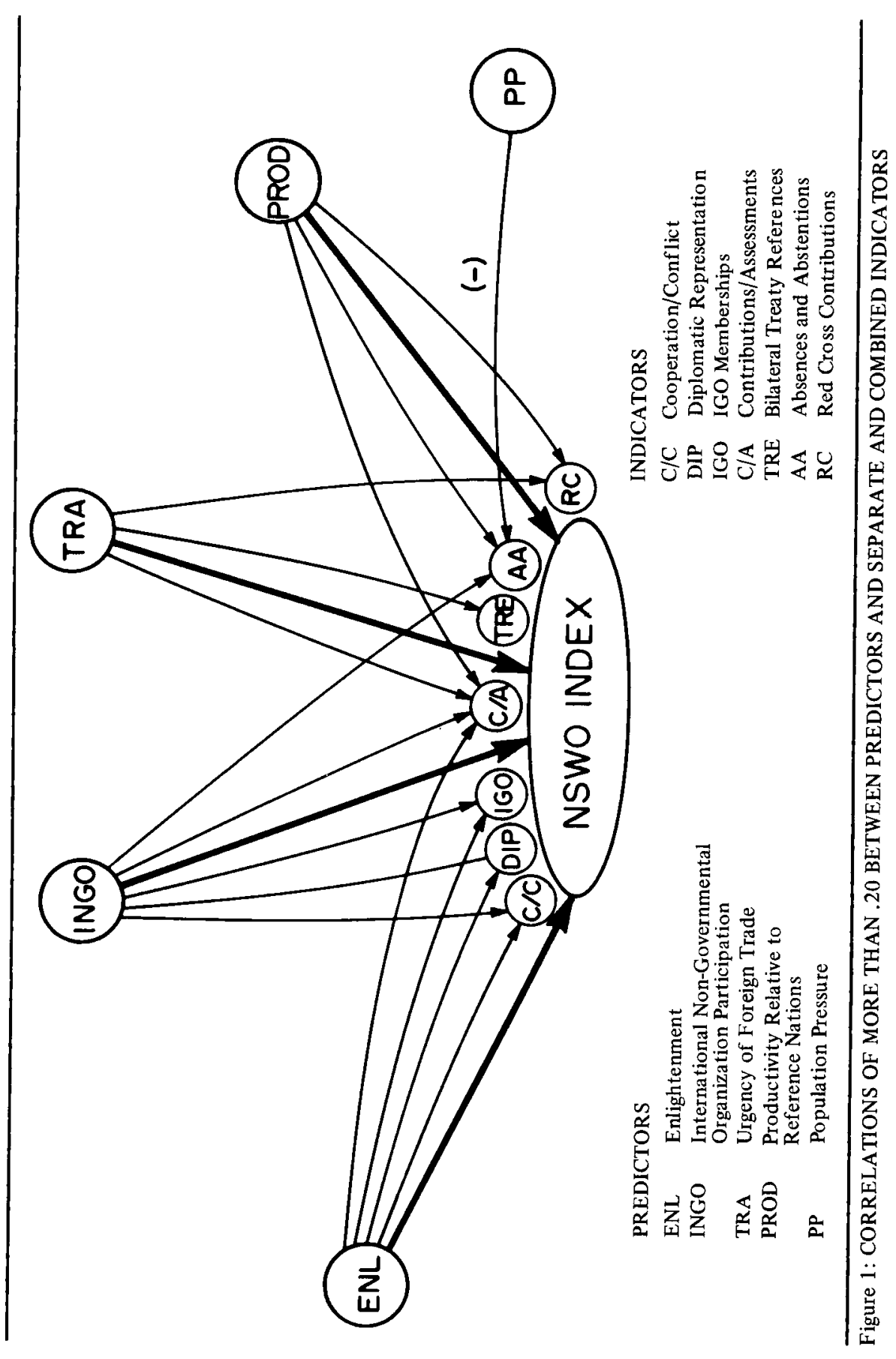


and abstentions, is also puzzling. It would be tempting to say that nations suffering from population pressure are unable to man their UN delegation were it not for the weak relationship between population pressure and diplomatic representation. On the other hand, the single highest correlation in the matrix, that between INGO participation and IGO memberships, is easily understood. The degree to which citizens of a nation have joined international nongovernmental organizations is likely to be reflected in the degree to which their governments join international governmental organizations.

\section{Relations of the Predictors to the NSWO Index}

The relation between the five predictors and the NSWO Index is complex and somewhat puzzling. To grasp its ramifications requires a step by step presentation. First, then, the zero-order correlations between the several predictors and the NSWO Index and the coefficients of determination (correlations squared) are shown in Table 4.

For relations among sociological variables, these are gratifying correlations. When it is recalled that the percentage proportion of the total variance of the criterion variables that is accounted for by each of the predictors is the square of the correlation coefficient, we note that INGO participation accounts for almost $32 \%$. And even urgency of foreign trade accounts for almost $10 \%$. Were the five predictors not correlated with one another, we would be able to explain more than three-quarters of the variance in the NSWO Index. Unfortunately, the linear regression model of the relationships among these variables suffers from multicollinearity-i.e., high correlations among independent variables, making it impossible to partition accurately the variance accounted for by the model among the predictors.

TABLE 4

RELATIONS BETWEEN THE PREDICTORS AND THE NSWO INDEX

\begin{tabular}{lcc}
\hline Predictor & $\begin{array}{c}\text { Zero-Order } \\
\text { Correlation }\end{array}$ & $\begin{array}{c}\text { Coefficient of } \\
\text { Determination }\end{array}$ \\
\hline INGO participation & .56 & .32 \\
Enlightenment & .44 & .19 \\
Productivity relative to reference nations & .38 & .14 \\
Urgency of foreign trade & .31 & .10 \\
Population pressure & -.15 & .02 \\
\hline
\end{tabular}


The two correlations that may be surprising are those for INGO participation and urgency of foreign trade. International nongovernmental organizations are generally regarded as having little influence on governments, whereas foreign trade is often regarded as significant to them.

It may be thought that the high correlation of INGO participation is in reality a case of reciprocal influence-that governments that support world order encourage their citizens to participate in INGOs, as well as the reverse. I attempted to examine this possibility by looking at the INGO scores of the Communist countries. It is usually assumed that they have discouraged their citizens from participating in international nongovernmental organizations (we know that they have often frowned upon their going abroad to attend meetings). We should therefore expect, if government policy is having an effect, that the rank of the Communist nations for INGO participation would be no higher than their rank on the NSWO Index. To my surprise, each of them except Albania had a higher rank on INGO participation that on the NSWO Index. In other words, there was no evidence that governmental policy is operating as a causal factor to keep down the INGO participation score.

Another possibility is that it is not the INGO participation itself that is having the marked effect but some factor or factors lying behind it, influencing both it and the NSWO Index. This possibility will be discussed after the analysis has been carried further.

The modest influence of urgency of foreign trade perhaps results from a feeling among governmental policy makers that the embodiment of the principle of freedom of the seas in international law already gives protection, so that no further strengthening of world order at this point is needed.

One has only to look at the lack of independence among the predictors as shown in Table 5 to realize that enlightenment is heavily overlapped

TABLE 5

INTERCORRELATIONS AMONG THE PREDICTORS

\begin{tabular}{lcccc}
\hline \hline & $\begin{array}{c}\text { Enlighten- } \\
\text { ment }\end{array}$ & $\begin{array}{c}\text { Urgency of } \\
\text { Foreign Trade }\end{array}$ & $\begin{array}{c}\text { Population } \\
\text { Pressure }\end{array}$ & $\begin{array}{c}\text { Productivity } \\
\text { Relative to } \\
\text { Reference Nations }\end{array}$ \\
\hline INGO Participation & .76 & .13 & -.10 & .24 \\
Enlightenment & & .46 & .04 & .41 \\
Urgency of Foreign & & & & .07 \\
$\quad \begin{array}{l}\text { Trade } \\
\text { Population Pressure }\end{array}$ & & & -.09 \\
\hline
\end{tabular}


with INGO Participation, urgency of foreign trade, and productivity relative to reference nations. Population pressure is clearly the predictor most independent of the others.

Multiple regression is the common technique for obtaining both the joint power of the independent variables in predicting the criterion variable and in determining the special contribution of each. The lack of independence among the predictors causes no problem for reaching the first objective, but it raises real obstacles to reaching the second. These obstacles will be considered after a brief discussion of the coefficient of multiple correlation.

A multiple correlation coefficient ignores the degree of independence of the predictors and simply states the degree of influence of all of them together on the criterion variable. In the present case, the multiple correlation with the NSWO Index is .69 . Squaring this, we see that all the predictors together explain $47 \%$ of the variance among the nations on the NSWO Index. In other words, more than half the variance is due to other factors not represented in the five predictors. This is somewhat disappointing, but is perhaps not surprising when one considers the multitude of influence that can affect a government's foreign policy.

Knowing the total effect of five predictors does not help as much in explaining the NSWO Index scores of the 114 nations as would knowing the contribution made by each. But when the predictors are not independent, there is no theoretically satisfying way by which to apportion accurately the influence represented by their overlap. To the degree that two predictors are overlapped, they are each representing the same force or influence, and they are doing so inseparably. Because of this, we must approach the problem in roundabout fashion. We will first discover the unique contribution of each predictor by comparing the amount by which the coefficient of determination of all five predictors taken together is reduced when a particular predictor is omitted from the calculation. This procedure reveals the amount this predictor contributes to the variance in the NSWO Index, apart from any overlap it has with other predictors. We can then discover the amount of variance that it shares with other predictors by subtracting this unique contribution from the simple coefficient of determination between it and the NSWO Index (see the second column, table 6). When this is done for the five predictors successively, it turns out that the overlaps are very great-nearly four times the explained variance left unexplained (.08) by the unique contributions. (If no predictor were overlapped with more than one other predictor, the sum of the overlaps would be twice the variance 


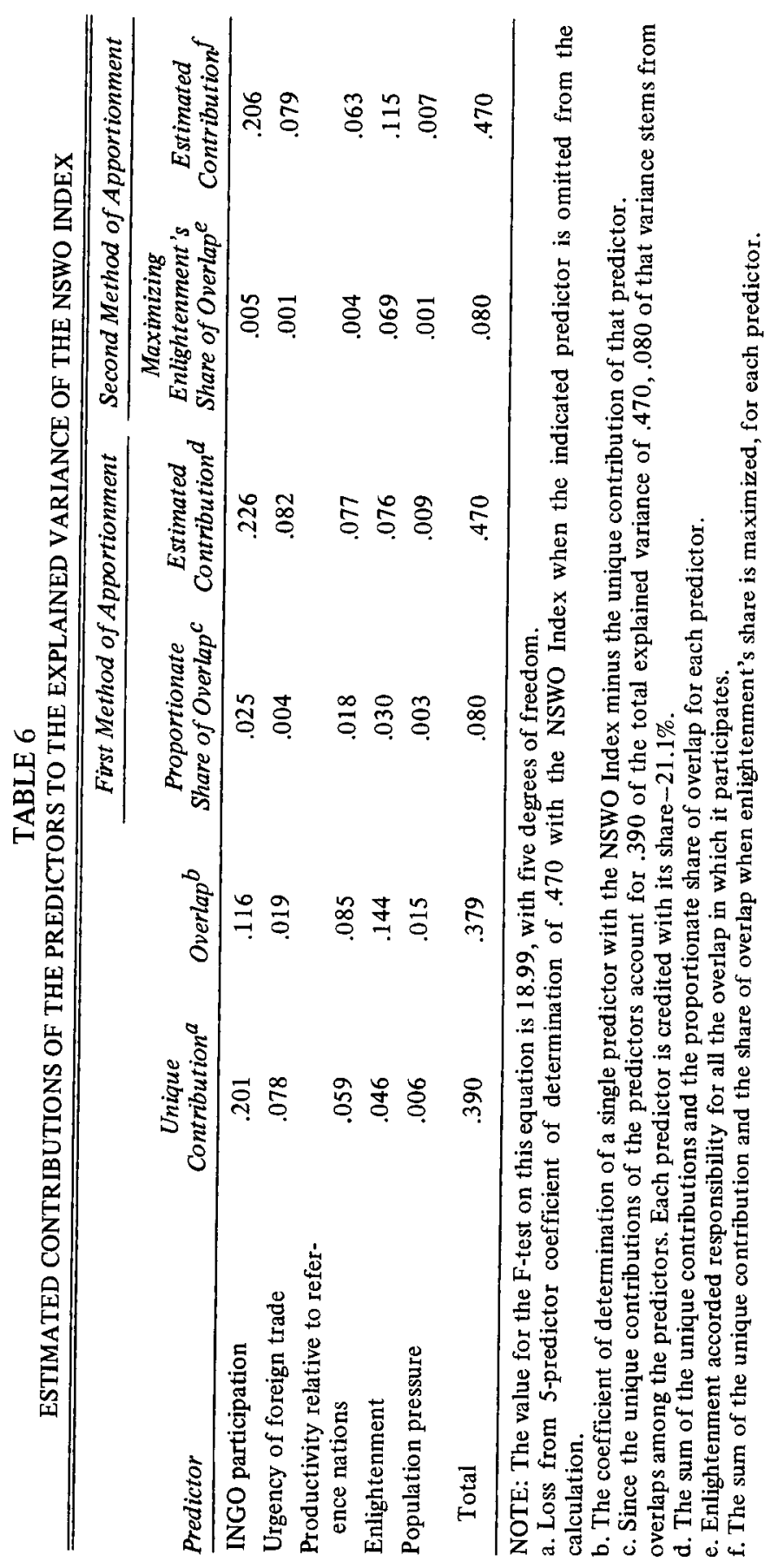


unexplained by the unique contributions. Hence, it is clear that predictors are overlapped more extensively than that, as is suggested by the correlations in Table 5.) We are therefore faced with the necessity of apportioning the explained variance unexplained by the unique contributions to the five predictors in some rational manner. The first method chosen is that of parcelling out this variance in accordance with the proportions of total overlap evidenced for each predictor. The proportion of overlap thus assigned to each predictor can then be added to the unique contribution of that predictor to yield an estimate of the amount of the total variance in the NSWO Index for which that predictor is responsible. The third and fourth columns of figures in Table 6 show the result of these procedures.

It can be argued that enlightenment, the predictor that has by far the most overlap, is a basic condition for INGO participation, productivity, foreign trade, and wide use of contraception and should therefore be allocated a greater than proportional share of the overlap. I have therefore made an alternative apportionment of the variance, shown in the last two columns of Table 6 . There enlightenment is accorded credit, so to speak, for all the overlap in which it participates (87\% of the total). The remaining share of the overlap is distributed among the other four predictors proportionally to their overlaps in column 2 of Table 6 . The second procedure as compared with the first affects the general picture most dramatically by raising the estimated contribution of enlightenment to the explained variance in the NSWO Index from .076 to .115 . Even so, INGO participation still makes a much greater contribution.

No matter how one looks at the results, it is clear that INGO participation is outstanding in significance. Its unique contribution alone is greater than the total contribution of any other predictor. A possible explanation of this rather surprising finding is that in the conferences and other activities sponsored by international nongovernmental organizations participants from different countries learn to work together and to appreciate one another's cultures. My earlier research supports this conclusion (Angell, 1969: ch. 9). It is probable that other forms of transnational participation examined in that work, such as study abroad, would also have correlated well with the NSWO Index if worldwide data had been available.

The three predictors next in their contributions to the variance in the NSWO Index are urgency of trade, enlightenment, and productivity relative to reference nations. Since the true significance of these three probably lies somewhere between the figures produced by the two 
procedures of calculation, we can perhaps say that they are roughly equal in influence. This rough equality represents a greater significance for urgency of foreign trade than would appear from its coefficient of determination with the NSWO Index in Table $4(.10)$, and less significance for enlightenment, whose coefficient was .19. These shifts are, of course, due to the considerably larger unique contribution of the former compared with that of the latter.

Table 5 shows that INGO participation and enlightenment are the most closely linked two predictors. This is in line with common sense. One would expect that the higher the level of enlightenment, the greater would be concern for world order. Enlightened populations would be prone to participation in international nongovernmental organizations, in part simply because they are in the network of world communication and in part because they see INGOs as bringing the peoples of the world closer together. There is probably some reverse influence also. Nations whose citizens have participated widely in INGOs are likely to be very aware of the importance in the modern world of schooling and the diffusion of information through the mass media.

The determination that foreign trade is a significant influence needs little comment. Perhaps the smallness of its contribution to the variance in the NSWO Index is the most interesting discovery made.

The result on productivity relative to reference nations lends support to the hypothesis that nations respond to relative economic success compared with other nations that they use as points of reference. It suggests that exploration to determine whether other kinds of world data would benefit from reference group analysis would be worthwhile.

Population pressure makes a very small contribution to the variance in the NSWO Index despite the fact that it is quite independent of the other predictors. Its zero-order correlation with the NSWO Index is so low that the connection between the two does not qualify for representation in Figure 1.

Together, INGO participation and urgency of foreign trade can account for $76 \%$ of the explained variance in the NSWO Index. The combined unique contributions of the other three predictors is only .11 (24\%) out of a total explained variance of .47. Thus, we have discovered two principal factors accounting for the NSWO scores, one much stronger than the other. The weaker represents participation in the world economy. The stronger represents both domestic and global social mobilization-enlightenment, and participation in international nongovernmental organizations. These are so typically modern phenomena that one is tempted to say that they are the wave of the future. 


\section{Practical Implications of the Analysis}

As stated earlier, this research has been aimed at contributing to the attainment of a more orderly world. The hope has been to learn what influences have brought some nations to support world order strongly so that men of good will in all nations might have guidance in choosing promising national policies.

How far down this road has the analysis brought us? Remembering that only $47 \%$ of the variance on the Index of National Support for World Order is accounted for by the five predictors that have been isolated, we cannot claim that it has carried us far. Yet, almost halfway is more than a start.

One of the encouraging features of the situation is that none of the five predictors is a national characteristic that is unchangeable, that could not be affected by public policy. We can therefore profitably discuss the implications of the findings as they relate to each predictor in turn.

Despite the considerable redundancy with INGO participation, it is obvious that the components of enlightenment-education and the mass media-are key building blocks in constructing an edifice of national concern for world order. This is encouraging, since no trends in the modern world are more consistent than the rising level of education and the increase in exposure to the mass media. These are trends that citizens concerned with realization of world order should find it easy to further, since they already have great momentum.

The significance of participation in international nongovernmental organizations has been clearly demonstrated, and there is, hence, a clear implication for policy. It would be conducive to world order if men of good will themselves joined such organizations or their national affiliates and encouraged by every possible means others to do likewise. The most strategic organizations are those that are worldwide in membership and free of the taint of ideology-political, racial, or religious. Since free governments cannot force such participation, and since, if forced by authoritarian governments, it would probably be less productive, the onus for furthering such a policy is on individual citizens and voluntary groups. Inversely, such groups can perform a vital service by preventing their governments from forbidding participation.

Because productivity relative to reference nations is a competitive concept, it is a moot question whether encouragement of productivity will have any general effect of increasing support for world order. Skeptics might say that relative position within the "league" is all that counts and that, for every nation that improves its position, another nation must 
decline in status. The counter-argument would be that competition will raise the whole level of productivity in the group of nations and that the rising level will inevitably bring with it an absolute increase in concern for world problems. From this standpoint, attempts to promote economic progress would pay off in terms of support for world order.

Although population pressure turned out to be a predictor of little significance, reduction of such pressure can be directly addressed in birth control and other reform programs. Moreover, there are other problems that I was unable to deal with for lack of data that may very well be distracting nations from their responsibility to further world order. Indeed, it is likely that any severe domestic problem tends to have this effect. No doubt the principal spur to alleviation of such problems will be worry about the domestic situation, but some citizens may be stimulated to added effort by the hope that success will also make possible greater national attention to global problems.

Urgency of foreign trade is probably the predictor least susceptible of intentional change, and, for that reason, it has fewer practical implications than do the others. Countries for the most part trade because trade will be beneficial to their economies. They are likely to do little more of it simply because this may have some influence toward world order.

\section{Unfinished Business}

Some may hold that there is little chance of advancing farther along the track so far pursued. Perhaps a large share of the $53 \%$ unexplained variance in the NSWO Index results from idiosyncratic conditions in particular countries that cannot be described in general terms and operationalized in predictors like those used here. Or a share of that variance may result from the particular relations of the members of pairs of nations, relations that would be impossible to deal with in worldwide terms.

Though undoubtedly such circumstances will prevent very high levels of prediction of national support for world order, it seems too early to conclude that we cannot improve on what has been accomplished here. A first step would be to see which nations' NSWO Index scores were least well predicted by our multiple regression equation. These are the nations on which unknown influences are having the greatest effect. They are revealed when their actual NSWO scores are compared with the scores that can be predicted from their scores on the five predictors, using the regression equation. In Table 7 are listed the nine nations whose actual 
TABLE 7

NATIONS WITH LARGEST GAPS BETWEEN ACTUAL AND PREDICTED NSWO INDEX SCORES

\begin{tabular}{|c|c|c|c|}
\hline \multicolumn{2}{|c|}{ Actual Higher than Predicted } & \multicolumn{2}{|c|}{ Actual Lower than Predicted } \\
\hline Gap & Nation & Gap & Nation \\
\hline 13.00 & Switzerland & 5.89 & Kenya \\
\hline 8.89 & Italy & 5.96 & Poland \\
\hline 8.14 & Ivory Coast & 5.99 & Malawi \\
\hline 7.87 & Demark & 6.16 & Gabon \\
\hline 7.75 & Thailand & 6.20 & Czechoslovakia \\
\hline 7.35 & Norway & 6.31 & Belgium \\
\hline 6.67 & Sweden & 6.34 & El Salvador \\
\hline 6.29 & Burma & 7.31 & Uganda \\
\hline \multirow[t]{4}{*}{5.78} & Liberia & 7.51 & South Africa \\
\hline & & 8.83 & Argentina \\
\hline & & 9.13 & Malta \\
\hline & & 9.17 & France \\
\hline
\end{tabular}

scores exceeded their predicted scores by more than one standard deviation on the scale in Table 2 and the twelve whose actual scores fell below their predicted scores by a like amount. Switzerland, whose gap is the widest in the first group, was in 1965 presumably being most affected by unknown positive influences. France, with the widest gap in the second group, was then presumably being most affected by unknown negative influences.

To find explanations for the unknown influence operating to produce these divergences, two courses are open. One is to attempt to obtain global data for those predictors that were abandoned for lack of such data. Of the twelve potential predictors listed, three were of this kind-immigration, the "PICA" Press Freedom Index, and students abroad. A number of other possibilities that required survey research data were never explored because it was known that such data were not available in many of the less developed countries. Any attempt to explore these possibilities will have to await the gathering of added data by existing international, national, and private agencies and the establishment in many countries of new facilities for data collection.

Another line of attack is to study carefully the 21 countries in Table 7 in the hope of hitting upon new hypotheses about the causes of national support for world order that can be tested. This appears to be the most promising line to follow. It may well be that case studies in depth will have to be undertaken before new fruitful hypotheses can be adumbrated. 


\section{REFERENCES}

ALGER, C. F. and S. J. BRAMS (1967) "Patterns of representation in national capitals and intergovernmental organizations." World Politics 19 (July): 646-663.

ANGELL, R. C. (1971) "A study of national willingness to take world responsibilities," pp. 19-30 in E. H. Fedder (ed.) The United Nations: Problems and Prospects. St. Louis: University of Missouri-St. Louis Center of International Studies.

-- (1969) Peace on the March: Transnational Participation. New York: Van Nostrand Reinhold.

COOLEY, C. H. (1918) Social Process. New York: Charles Scribner's.

CUTRIGHT, P. (1965) "Political structure, economic development, and national security programs." Amer. J. of Sociology 70 (March): 537-550.

DEUTSCH, K. W. (1953) Nationalism and Social Communication: an Inquiry into the Foundations of Nationality. New York: MTT Press and John Wiley.

GALTUNG, J. (1967) "On the future of the international system." J. of Peace Research 1967, 4: 305-333.

KEOHANE, R. (1969) "Who cares about the General Assembly?" International Organization 23 (February): 141-149.

McClELlaND, C. A. and G. D. HOGGARD (1969) "Conflict patterns in the interaction among nations," in J. N. Rosenau (ed.) International Politics and Foreign Policy. New York: Free Press.

MORGENTHAU, H. (1967) Politics among Nations. New York: Alfred A. Knopf.

ROHN, P. H. (1968) "The United Nations Treaty Series Project." International Studies Q. (June): 174-195.

TAYLOR, C. L. and M. C. HUDSON (1972) World Handbook of Political and Social Indicators II. New Haven, Conn.: Yale Univ. Press.

\section{the $A P A$ MONITOR Beginning January 1971}

The official newspaper of the American Psychological Association. An illustrated monthly designed to promote communication among the members of APA. Immediate coverage of news and events affecting the behavioral sciences. Updated reviews of grant assignments; the results of studies; in-depth feature articles-all serving to keep the psychologist closely attuned to contemporary issues relevant to the profession.

monthly -12 issues per year

Subscription price: $\$ 3.00$

American Psychological Association

$1200-17$ th Street, N.W.

Wakington, D.C. 20036 